\title{
Heat Shock Protein Expression in Vulnerable Cells of the Rat Hippocampus as an Indicator of Excitation-induced Neuronal Stress
}

\author{
Robert S. Sloviter ${ }^{1}$ and Daniel H. Lowenstein ${ }^{2}$ \\ 'Neurology Research Center, Helen Hayes Hospital, New York State Department of Health, West Haverstraw, New York \\ 10993 and Departments of Pharmacology and Neurology, College of Physicians and Surgeons, Columbia University, New \\ York, New York 10032, and 'Epilepsy Research Laboratory, Department of Neurology, University of California at San \\ Francisco, San Francisco, California 94143
}

The inducible 72 kDa heat shock protein (HSP72) has been shown to be protective in non-neuronal cells and neurons in culture, but its function and the control of its expression in the CNS are poorly understood. Although HSP72 is induced in neurons in vivo by neurotoxic compounds that produce seizures and neuronal damage, it is unknown if its expression is a specific response to excitation per se or to "stressful" or potentially injurious excitation, or if it is a marker or mediator of irreversible injury. We have attempted to identify the nature of the stimulus for HSP72 expression by utilizing focal electrical stimulation that can either excite or destroy postsynaptic cells, depending on the duration of afferent stimulation. Previous studies have demonstrated that intermittent stimulation of the main hippocampal afferent pathway for $24 \mathrm{hr}$ evokes synchronous discharges in dentate granule cells but does not injure them. However, the same stimulation irreversibly destroys three of the four cell populations innervated by the granule cells. The three vulnerable populations are the dentate hilar mossy cells, the somatostatin/neuropeptide $Y$ (NPY)-immunoreactive hilar neurons, and the CA3c pyramidal cells. The fourth and relatively resistant population is the GABA-immunoreactive dentate basket cells. In this study, we have localized HSP72 expression immunocytochemically in the hippocampal dentate gyrus in response to nontoxic durations of potentially neurotoxic afferent stimulation. One hour of perforant path stimulation, which evoked granule cell spikes and epileptiform discharges and aberrant NPY expression in virtually all granule cells 1 d later, evoked no detectable HSP72 immunoreactivity in any hippocampal neurons. However, $1 \mathrm{~d}$ after stimulation for 2-6 hr, HSP72 immunoreactivity was observed in the seizuresusceptible dentate hilar cells and CA3c neurons that would have died had stimulation continued. Despite being directly and repetitively activated by the afferent stimulation, the relatively seizure-resistant granule cells and dentate pyramidal-shaped basket cells did not express detectable HSP72 immunoreactivity. These results indicate that HSP72 ex-

\footnotetext{
Received Dec. 3, 1991; revised Feb. 7, 1992; accepted Mar. 10, 1992.

We thank Anne Sollas for expert technical assistance, Dr. H. E. Scharfman for constructive criticism of the manuscript, and Drs. K. G. Baimbridge and W. J. Welch for generously providing antisera. This work was supported by U.S. Public Health Service Grants NS18201 (R.S.S.), DA05496 (R.S.S.), and NS01424 (D.H.L.) and by a grant from the American Epilepsy Society (D.H.L.).

Correspondence should be addressed to Dr. R. S. Sloviter, Neurolugy Research Center, Helen Hayes Hospital, West Haverstraw, NY 10993.

Copyright (C) 1992 Society for Neuroscience $0270-6474 / 92 / 123004-06 \$ 05.00 / 0$
}

pression is a sensitive and cell-specific response to potentially injurious neuronal stress caused by repetitive excitatlon, and is a marker neither of irreversible cell injury nor of nonstressful excitation.

A characteristic pattern of neuronal loss is evident in the hippocampus of many patients who suffer from temporal lobe epilepsy (Meldrum and Corsellis, 1984). The study of differences between vulnerable and resistant ncuron populations may elucidate the intrinsic protective mechanisms that enable some neurons to survive insults that are lethal to other cells. Recent studies in the human and rat hippocampus suggest that neuronal vulnerability or resistance to seizures may be related to cellspecific differences in the constitutive or reactive expression of calcium-binding proteins (Sloviter, 1989; Sloviter et al., 1991), which may prevent lethal increases in free intracellular calcium (Baimbridge and Miller, 1982). Another protective mechanism may involve the expression of the inducible heat shock protein HSP72, which is a member of the family of $70 \mathrm{kDa}$ heat shock proteins (Brown, 1990). HSP72 is synthesized in response to a variety of insults, including heat, ischemia, or seizures (Johnston and Kucey, 1988; Riabowol et al., 1988; Lowenstein et al., 1990; Nowak et al., 1990; Simon et al., 1991), and there is an association between HSP72 expression and relative protection from light-induced retinal damage and global ischemia (Barbe et al., 1988; Kitagawa et al., 1990; Kirino et al., 1991). However, little is known about the nature of the stimuli that provoke HSP72 expression in vivo. A major question requiring resolution is whether neuronal HSP72 expression is a specific response to "stressful" stimuli, or if it is primarily a marker or mediator of irreversible injury. In one recent study, it was noted that HSP72 immunoreactivity was induced in hippocampal neurons of kainate-treated rats, but only in animals that exhibited status epilepticus and neuronal degeneration (Vass et al., 1989). No HSP72 expression was noted in a series of kainate-treated animals that exhibited seizures but no neuronal damage.

In this study, we have utilized a focal stimulation model in the rat to characterize the relationship between cell excitation, cell stress, and HSP72 expression. The perforant path stimulation model involves unilateral, intermittent electrical stimulation of the main excitatory afferent to the hippocampus (Sloviter, 1983, 1991). If stimulation evokes granule cell discharges for $24 \mathrm{hr}$, vulnerable cells innervated by the granule cells are destroyed. The resulting pattern of cell loss and survival after perforant path stimulation in the rat is virtually identical to that 
seen in the human epileptic hippocampus (Meldrum and Corsellis, 1984; de Lanerolle et al., 1989; Sloviter et al., 1991).

Given the degree of control inherent in experiments that utilize focal electrical stimulation as the activation stimulus, it is possible to "stress" vulnerable hippocampal cells without killing them. This is accomplished by stimulating for a duration that repetitively activates the hippocampal network without damaging it. Using this approach, it can be determined if HSP72 is synthesized in response to prolonged excitation per se or to neuronal stress that occurs only as the threshold for injury is approached, or if HSP72 is only produced as part of the process of irreversible injury. It is also possible to determine if HSP72 is expressed in all activated cells, or if the pattern of expression corresponds to the known vulnerability or resistance of distinct neuronal subpopulations. Therefore, we have unilaterally and intermittently stimulated the perforant pathway of rats for $1-6$ $\mathrm{hr}$ and then localized HSP72-like immunoreactivity $1 \mathrm{~d}$ later. The pattern of HSP72 immunoreactivity was compared to the patterns of neuropeptide Y (NPY) immunoreactivity and parvalbumin (PV) immunoreactivity for two reasons. First, NPY and $P V$ are markers of distinct populations of vulnerable and resistant dentate hilar neurons and basket cells of the granule cell layer (Sloviter, 1991). Therefore, staining for NPY-, PV-, and HSP72-like immunoreactivities in adjacent sections allows a comparison to be made between the locations and morphologies of these distinct cell populations and the cells that express HSP72 in response to stimulation. Second, since we observed in pilot experiments that perforant path stimulation evoked NPY expression in granule cells, which do not normally express it, its presence attests to the efficacy of the stimulation in producing aberrant protein synthesis whether or not HSP72 is expressed by the same stimuli.

\section{Materials and Methods}

Animal treatment. Male Sprague-Dawley descendant rats (250-350 gm) were treated in accordance with the guidelines set by the New York State Department of Health and the National Institutes of Health for the humane treatment of animals. Rats were anesthetized with ether and then given urethane ( $1.25 \mathrm{gm} / \mathrm{kg}$, s.c.; $250 \mathrm{mg}$ urethane $/ \mathrm{ml}$ saline). Bipolar stainless steel stimulating electrodes (NE-200, Rhodes Medical) were placed in the angular bundles of both sides of the brain and $4 \mathrm{M}$ $\mathrm{NaCl}$-filled glass recording electrodes were lowered into each dentate gyrus. Extracellular granule cell field potentials were evoked and recorded as previously described (Sloviter, 1991). One angular bundle was stimulated continuously at $2 \mathrm{~Hz}$. (paired pulses $40 \mathrm{msec}$ apart) with intermittent $10 \mathrm{sec}$ trains of single stimuli at $20 \mathrm{~Hz}$ delivered through the same electrode once per minute for $1,2,4,6$, or $24 \mathrm{hr}$. Stimulus voltage was above the threshold needed to evoke granule cell population spikes of maximal amplitude. Supplemental subcutaneous injections of urethane were given to maintain surgical anesthesia, and ointment (Duratears, Alcon) was applied to the surface of the eyes to prevent ocular injury due to drying. Body temperature was maintained at $38 \pm 0.1^{\circ} \mathrm{C}$ by a thermostatically controlled heating blanket (Harvard Apparatus). At the end of the stimulation, the skull was swabbed with Betadine solution, and stainless steel wound clips were used to close the incision. Rats were kept warm with an incandescent light while they recovered from anesthesia. Control rats $(n=6)$ were often prepared at the same time as experimental animals using a second stereotaxic device. Controls were treated identically except that no stimuli wcre delivercd during the period after initial electrode placement.

Perfusion fuxation. One day after the end of stimulation, rats were anesthetized with urethane and fixed by perfusion through the heart by gravity feed. For silver impregnation degeneration staining, rats were perfused with saline for $3 \mathrm{~min}$ followed by $4 \%$ paraformaldehyde in 0.1 M phosphate buffer, $\mathrm{pH} 7.4$, for $10 \mathrm{~min}$. For immunocytochemistry, rats were perfused (without saline prewash) for $3 \mathrm{~min}$ with ice-cold $2 \%$ paraformaldehyde in $0.1 \mathrm{~m}$ sodium acetate buffer, $\mathrm{pH} 6.5$, followed by 30 min of perfusion with ice-cold $2 \%$ paraformaldehyde, $0.1 \%$ glutar- aldehyde in $0.1 \mathrm{M}$ sodium borate buffer, pH 8.5. Brains were kept in situ overnight at $4^{\circ} \mathrm{C}$ and then removed and cut in the coronal plane using a Vibratome. For Nissl staining, 20- $\mu \mathrm{m}$-thick sections were mounted directly onto chrom alum- and gelatin-coated glass slides and air dried. Slides were dehydrated in graded alcohols and xylene, rehydrated, stained with $1.0 \%$ cresyl violet, dehydrated, and coverslipped with Permount. For silver degeneration or immunocytochemical staining, $50-\mu \mathrm{m}$-thick sections were cut and collected in $0.1 \mathrm{~m}$ Tris buffer, $\mathrm{pH} 7.4$. Alternate sections of each brain were collccted sequentially in different bins so that matching sets of sections from different parts of the hippocampus could be obtained for each of several different antisera. Freely floating sections were stained using a silver impregnation method for degenerating cells and fibers (Nadler and Evenson, 1983) or by immunocytochemistry as previously described (Sloviter, 1989). Sections were incubated overnight at $4^{\circ} \mathrm{C}$ in polyclonal rabbit antisera raised against parvalbumin (1:1000; provided by Dr. K. G. Baimbridge) or neuropeptide Y (1:2000 dilution; Peninsula). For HSP72 immunocytochemistry, sections were incubated in $10 \%$ horse serum for $1 \mathrm{hr}$ and then mouse monoclonal antibody raised against $\operatorname{HSP} 72$ (1:50,000; provided by Dr. W. J. Welch). Immunocytochemical controls were of two types. Some sections were incubated in buffer without antiserum, and others were incubated in normal rabbit serum (diluted 1:1000-1:5000) instead of primary antiserum. Neither treatment resulted in specific staining.

\section{Results}

\section{Hilar cell injury after perforant path stimulation}

Unilateral, intermittent perforant path stimulation for $24 \mathrm{hr}$, which evoked granule cell population spikes and multiple discharges throughout the period of stimulation, selectively damaged hilar neurons throughout the dorsal hippocampus on the stimulated side as revealed by silver degeneration stain $1 \mathrm{~d}$ after the end of stimulation (Fig. $1 A, B$ ). As previously reported (Sloviter, 1991), the only dentate cells that were damaged were those whose cell bodies were within the dentate hilus. The GABAimmunoreactive pyramidal-shaped basket cells of the granule cell layer were not similarly vulnerable. One week later, Nissl staining revealed that the majority of dentate hilar neurons had degenerated (Fig. 1C,D). The morphological and functional consequences of $24 \mathrm{hr}$ of perforant path stimulation have been described in detail previously (Sloviter, 1991). Stimulation for 1, 2, 4, or $6 \mathrm{hr}$ produced no silver-impregnated hippocampal neurons 1-3 d after stimulation (data not shown) and no apparent loss of hilar cells 2 weeks later (Fig. $1 E$ ).

\section{HSP72 expression after nontoxic perforant path stimulation}

Control animals exhibited no NPY-like immunoreactivity in the dentate granule cells and no HSP72-like immunoreactivity anywhere except in a few neocortical, CAl pyramidal, and dentate granule cells in the path of the recording electrodes. Repetitive perforant path stimulation for $1 \mathrm{hr}$, which evoked granule cell discharges throughout the stimulation period, provoked aberrant NPY immunoreactivity in granule cells 24 hr later ( $n$ $=4$ ), but no detectable HSP72 expression. One day after stimulation for $2 \mathrm{hr}$ or more, many dentate hilar neurons, a few area CA $3 c$ cells, and a few astrocytes of the stimulated dorsal hippocampus exhibited HSP72 immunoreactivity (Figs. $1 F-H, 2$ ). HSP72 expression was induced in one of two rats stimulated for $2 \mathrm{hr}$, three of four rats stimulated for $4 \mathrm{hr}$, and in five of six rats stimulated for $6 \mathrm{hr}$. Although HSP72 staining was relatively faint a day after $2 \mathrm{hr}$ of stimulation, 4 and $6 \mathrm{hr}$ of stimulation evoked intense staining (Fig. $1 G, H$ ). HSP72 immunoreactivity was present in a large number of dentate hilar neurons throughout the dorsal half of the hippocampus (Fig. 2B-E).

Hilar cells exhibited HSP72 immunoreactivity throughout the soma and dendrites. These hilar neurons were nearly exclusively those whose somata and dendrites were contained entirely with- 

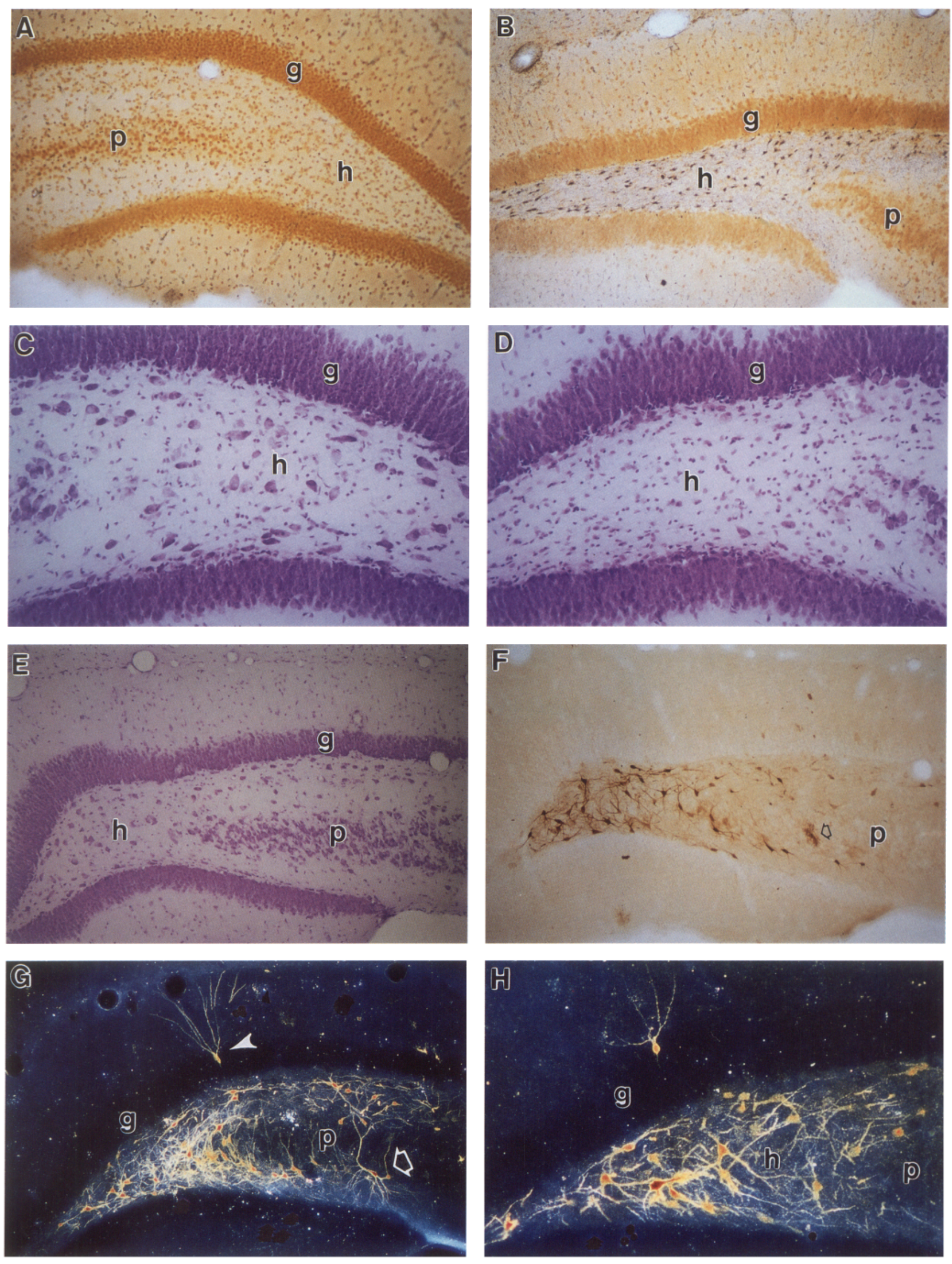
in the hilus. In only one case was an immunoreactive hilar cell dendrite followed through the granule cell layer into the dentate molecular layer, where it bifurcated just above the granule cell layer. Occasionally, a small number of astrocytes in the dentate hilus and area $\mathrm{CA} 3 \mathrm{c}$ were $\mathrm{HSP} 72$ immunoreactive in stimulated rats (Fig. $1 F$, arrow).

Granule cells were very rarely HSP72 immunoreactive. When granule cells were immunoreactive (Fig. $1 G, H$ ), they were usually in the path of the recording electrode. In sections containing hundreds of granule cells, HSP72 immunoreactivity was never observed in more than two granule cells per section. Despite the lack of detectable HSP72 immunoreactivity in granule cells, even 1 hr of stimulation evoked aberrant NPY expression (Fig. $2 G, H)$ in the soma and axons of virtually all granule cells, which do not normally express it. Comparison of the location and morphology of the HSP72-immunoreactive hilar neurons with the location and morphology of the PV-immunorcactive dentate cells of the granule cell layer (Fig. $2 F$ ) indicates that the relatively seizure-resistant inhibitory pyramidal-shaped basket cells (Sloviter, 1987, 1991), which possess ascending dendrites and form the axosomatic plexus in the granule cell layer (Amaral, 1978), did not express HSP72 in response to perforant path stimulation. Thus, HSP72 expression was selectively induced in the previously identified dentate hilar and CA3c pyramidal cells that would have died had stimulation continued (the silverimpregnated cells shown in Fig. $1 B$ ).

HSP72 immunoreactivity was seen occasionally in a few hilar cells in the contralateral dentate gyrus, but never in CA1, CA2, CA3a, or CA3b pyramidal cells of either hippocampus after 2$6 \mathrm{hr}$ of stimulation. HSP72 immunoreactivity was not seen in the entorhinal cortex, which was presumably activated antidromically by the perforant path stimulation, or in any brain region other than the hippocampal dentate gyrus.

\section{Discussion}

These results demonstrate that (1) repetitive excitation of granule cells for $1 \mathrm{hr}$, which induced aberrant NPY expression in virtually all granule cells, evoked no detectable HSP72 expression in any hippocampal neurons; (2) longer durations of stimulation that approached, but did not reach, the threshold for injury reliably evoked HSP72 expression; (3) HSP72 expression was evoked only in the vulnerable hippocampal cell populations that would have died had stimulation continued; and (4) despite direct excitatory activation, the relatively seizure-resistant dentate neurons, that is, granule and basket cells (Sloviter, 1987, 1991), did not express detectable HSP72 immunoreactivity. However, this is clearly not due to an inability to express the protein since perforant path stimulation for $24 \mathrm{hr}$ or kainic acid- induced seizures induced HSP72 expression in numerous dentate granule cells (R. S. Sloviter and D. H. Lowenstein, unpublished observations).

These observations, obtained with a highly controlled model for reliably delivering sublethal neuronal stress, clarify the possible significance of HSP72 expression in several ways. First, neuronal HSP72 expression is not an indicator of inevitable injury or a marker of cell injury since sublethal stimulation evoked its expression. Second, the lack of HSP72 expression in animals stimulated for $1 \mathrm{hr}$ indicates that HSP72 is not a marker of prolonged neuronal excitation per se; it is expressed only as the threshold for injury is approached. The fact that HSP72 was not expressed in all dentate neurons, but only in the cells that are most vulnerable to excessive excitation, indicates that HSP72 expression is a sensitive and specific indicator of excitationinduced and potentially injurious cell stress.

Two additional observations merit comment. The first is the finding that afferent activation of granule cells produced NPY expression in granule cell somata and axons. This is notable because the granule cells do not normally exhibit NPY immunoreactivity. Aberrant or increased expression of NPY has been reported previously in kainate-treated rats (Marksteiner et al., 1990) and after electroconvulsive shocks (Wahlestedt et al., 1990), but it is of unknown significance. In these experiments, it primarily attests to effective granule cell activation and aberrant protein expression regardless of whether or not HSP72 was expressed in the same cells. The second observation of note is the HSP72 expression in a few hippocampal astrocytes. The significance of this finding is not apparent.

The selective expression of HSP72 in some, but not all, dentate cell types that were presumably excited by the granule cell discharges is intriguing. Clearly, it cannot be assumed that all postsynaptic cell types that receive monosynaptic excitatory input from the granule cells are excited to precisely the same degree by the same presynaptic discharges (Scharfman, 1991). Given this caveat, we tentatively infer that, despite being excited, the relatively resistant granule cells and their associated inhibitory basket cells did not express HSP72 because the excitation to which they were subjected was not sufficiently stressful to them. If the selective expression of HSP72 is due to intrinsic postsynaptic differences among the different cell types, it would be of considerable significance to identify the cell-specific processes that determine whether or not a particular degree of excitation is bearable.

Our observations also raise the following question: how are "stressful" excitatory stimuli translated into a signal for HSP72 induction? Previous studies have suggested that HSP72 expression may be a protective response to toxic conditions that cause abcrrant protcin folding and translocation of intraccllular pro-

Figure 1. Perforant path stimulation-induced HSP72 expression in the rat dentate gyrus. $A$, Silver-stained section from sham control. Note that uninjured cells appear yellow. $B$, One day after the end of $24 \mathrm{hr}$ of perforant path stimulation, black, silver-impregrated cells are visible in the dentate hilus $(h)$. Note that cells of the granule cell $(g)$ and pyramidal cell $(p)$ layers are not silver impregnated. $C$ and $D$, Unstimulated $(C)$ and stimulated $(D)$ sides of a rat $5 \mathrm{~d}$ after $24 \mathrm{hr}$ of unilateral perforant path stimulation. Note extensive loss of hilar neurons on the stimulated side. $E$, Cresyl violet-stained dentate gyrus $1 \mathrm{~d}$ after $6 \mathrm{hr}$ of perforant path stimulation showing normal morphology. $F$, HSP72 immunoreactivity in a section adjacent to the one shown in $E$. Note that the location of the HSP72-immunoreactive hilar neurons is similar to the location of the vulnerable hilar cells silver impregnated in $B$. Also note an HSP72-immunoreactive astrocyte (arrow). $G$, Dark-field illumination of HSP72 immunoreactivity in the same animal shown in $E$ and $F$. Note HSP72 expression in hilar cells, CA3c neurons (arrow), and one granule cell (arrowhead) on the stimulated side. The immunoreactive granule cell was along the recording electrode track and may have suffered physical injury. $H$. HSP72 immunoreactivity in an animal stimulated for $4 \mathrm{hr}$ and killed $1 \mathrm{~d}$ later. Note similar immunoreactive hilar neurons and a single immunoreactive granule cell that did not appear in the same plane with a recording electrode track. Magnification: $62.5 \times$ in $A, B, E$, and $F ; 125 \times$ in $C, D, G$, and $H$. 


teins. Although hed, hypoxia, acidosis, or the incorporation of amino acid analogs into abnormal proteins are effective inducers of HSP72 (Welch, 1990), exposure to calcium ionophores or glutamate is not (Watowich and Morimoto, 1988; Lowenstein et al., 1991). It remains to be determined which, if any, of the known induction mechanisms initiated the HSP72 expression in this study, or if prolonged excitation involves a novel mechanism.

Although these experiments indicate that HSP72 expression is an indicator of potentially injurious neuronal stress, the results shed no light on the question of whether HSP72 expression in vivo is neuroprotective. Studies of non-neuronal cells in vitro have demonstrated that the interruption of HSP72 expression after a mild heat shock blocks the development of thermotolerance, which is the ability of a cell to tolerate a normally toxic heat shock (Johnston and Kucey, 1988; Riabowol et al., 1988). Although direct evidence for a protective role in neurons in vivo is lacking, it has been demonstrated that the induction of HSP72 expression in cultured cerebellar granule cells by mild heat shock is associated with thermotolerance and resistance to normally toxic glutamate concentrations (Lowenstein et al., 1991). Studies of light-induced retinal damage in the rabbit (Barbe et al., 1988) and of global ischemia in rats (Kitagawa et al., 1990; Kirino et al., 1991) show an association between HSP72 expression and a decrease in neuronal injury. Whether the HSP72 expression in the prescnt study makes vulncrable dentate hilar cells less vulnerable, as in vitro injection of a calcium-chelating agent has been shown to do (Scharfman and Schwartzkroin, 1989), remains to be determined.

\section{References}

Amaral DG (1978) A Golgi study of cell types in the hilar region of the hippocampus in the rat. J Comp Neurol 182:851-914.

Baimbridge KG, Miller JJ (1982) Immunohistochemical localization of calcium-binding protein in the cerebellum, hippocampal formation and olfactory bulb of the rat. Brain Res 245:223-229.

Barbe MF, Tytell M, Gower DJ, Welch WJ (1988) Hyperthermia protects against light damage in the rat retina. Science 241:18171820.

Brown IR (1990) Induction of heat shock (stress) genes in the mammalian brain by hyperthermia and other traumatic events: a current perspective. J Neurosci Res 27:247-255.

de Lanerolle NC, Kim JH, Robbins RJ, Spencer DD (1989) Hippocampal interneuron loss and plasticity in human temporal lobe epilepsy. Brain Res 495:387-395.

Johnston RN, Kucey BL (1988) Competitive inhibition of hsp 70 gene expression causes thermosensitivity. Science 242:1551-1554.

Kirino T, Tsujita Y, Tamura A (1991) Induced tolerance to ischemia in gerbil hippocampal neurons. J Cereb Blood Flow Metab 11:299307.

Kitagawa K, Matsumoto M, Tagaya M, Hata R, Ueda H, Niinobe M, Handa N, Fukunaga R, Kimura K, Mikoshiba K, Kamada T (1990) Ischemic tolerance phenomenon found in the brain. Brain Res 528: 21-24.

Lowenstein DH, Chan P, Miles M (1991) The stress protein response in cultured neurons: characterization and evidence for a protective role in excitotoxicity. Neuron 7:1053-1060.

Lowenstein DH, Simon RP, Sharp FR (1990) The pattern of 72-kDa heat shock protein-like immunoreactivity in the rat brain following flurothyl-induced status epilepticus. Brain Res 531:173-182.

Marksteiner J, Ortler M, Bellmann R, Sperk G (1990) Neuropeptide $\mathrm{Y}$ biosynthesis is markedly induced in mossy fibers during temporal lobe epilepsy of the rat. Neurosci Lett 112:143-148.

Meldrum BS, Corsellis JAN (1984) Epilepsy. In: Greenfield's neuropathology (Corsellis JAN, Duchen LW, eds), pp 921-950. New York: Wiley.

Nadler JV, Evenson DA (1983) Use of excitatory amino acids to make axon-sparing lesions of hypothalamus. Methods Enzymol 103:393400.

Nowak TS Jr, Bond U, Schlesinger MJ (1990) Heat shock RNA levels in brain and other tissues after hyperthermia and transient ischemia. J Neurochem 54:451-458.

Riabowol KT, Mizzen LA, Welch WJ (1988) Heat shock is lethal to fibroblasts microinjected with antibodies against hsp70. Science 242: $433-436$

Scharfman HE (1991) Dentate hilar cells with dendrites in the molecular layer have lower thresholds for synaptic activation by perforant path than granule cells. J Neurosci 11:1660-1673.

Scharfman HE, Schwartzkroin PA (1989) Protection of dentate hilar mossy cells from prolonged stimulation by intracellular calcium chelation. Science 246:257-260.

Simon RP, Cho H, Gwinn R, Lowenstein DH (1991) The temporal profile of 72-kDa heat shock protein expression following global ischemia. J Neurosci 11:881-889.

Sloviter RS (1983) "Epileptic" brain damage in rats induced by sustained electrical stimulation of the perforant path. I. Acute electrophysiological and light microscopic studies. Brain Res Bull 10:675697.

Sloviter RS (1987) Decreased hippocampal inhibition and a selective loss of interneurons in experimental epilepsy. Science 235:73-76.

Sloviter RS (1989) Calcium-binding protein (calbindin-D28k) and parvalbumin immunocytochemistry: localization in the rat hippocampus with specific reference to the selective vulnerability of hippocampal neurons to seizure activity. J Comp Neurol 280:183-196.

Sloviter RS (1991) Permanently altered hippocampal structure, excitability and inhibition after experimental status epilepticus in the rat; the "dormant basket cell" hypothesis and its possible relevance to temporal lobe epilepsy. Hippocampus 1:41-66.

Sloviter RS, Sollas AL, Barbaro NM, Laxer KD (1991) Calciumbinding protein (calbindin-D28K) and parvalbumin immunocytochemistry in the normal and epileptic human hippocampus. J Comp Neurol 308:381-396.

Vass K, Berger ML, Nowak TS Jr, Welch WJ, Lassmann H (1989) Induction of stress protein HSP70 in nerve cells after status epilepticus in the rat. Neurosci Lett 100:259-264.

Wahlestedt C, Rlendy JA, Kellar KJ, Heilig M, Widerlöv E, Ekman R (1990) Electroconvulsive shocks increase the concentration of neocortical and hippocampal neuropeptide Y (NPY)-like immunoreactivity in the rat. Brain Res 507:65-68.

Watowich SS, Morimoto RI (1988) Complex regulation of heat shockand glucose responsive genes in human cells. Mol Cell Biol 8:393405 .

Welch W (1990) The mammalian stress response: cell physiology and biochemistry of stress proteins. In: Role of the heat shock or stress protein response in human disease and medicine (Morimoto R, Georgopoulos C, Tissieres A, eds), pp 223-278. Cold Spring Harbor, NY: Cold Spring Harbor Laboratory.

\footnotetext{
Figure 2. HSP72, NPY, and PV immunoreactivity in the dentate gyrus $1 \mathrm{~d}$ after $6 \mathrm{hr}$ of perforant path stimulation. $A$, Cresyl violet-stained section showing normal dentate morphology. $B-E$. HSP72 immunoreactivity in progressively more caudal sections of the dentate gyrus on the stimulated side. $F, \mathrm{PV}$ immunoreactivity of an alternate section of the same brain showing the locations and morphology of dentate basket cells. Note that the PV-immunoreactive cells with ascending dendrites are not HSP72 immunoreactive in $B-E$. $G$, NPY immunoreactivity in a sham control. Note that NPY immunoreactivity is normally present in hilar neurons but not granule cells. $H$, NPY immunoreactivity in the stimulated animal shown in $A-F$. Note aberrant NPY expression in granule cell somata $(g)$ and mossy fiber axons in the hilus $(h)$ and CA3 pyramidal cell layer $(p)$. Magnification: $125 \times$ in $A-F ; 62.5 \times$ in $G$ and $H$.
} 